\title{
Creating a library holding group: an approach to large system integration
}

\author{
Isaac R. Huffman, MSLS, AHIP; Heather J. Martin, MISt, AHIP; Basia Delawaska-Elliott, MLIS \\ See end of article for authors' affiliations. \\ DOI: http://dx.doi.org/10.3163/1536-5050.104.4.013
}

\begin{abstract}
Purpose: Faced with resource constraints, many hospital libraries have considered joint operations. This case study describes how Providence Health \& Services created a single group to provide library services.
\end{abstract}

Methods: Using a holding group model, staff worked to unify more than 6,100 nonlibrary subscriptions and 14 internal library sites.

Results: Our library services grew by unifying 2,138 nonlibrary subscriptions and 11 library sites and hiring more library staff. We expanded access to 26,018 more patrons.

Conclusions: A model with built-in flexibility allowed successful library expansion. Although challenges remain, this success points to a viable model of unified operations.

Keywords: Medical Subject Headings: Efficiency, Organizational*; Information Storage and Retrieval/Statistics \& Numerical Data*; Libraries, Hospital/Organization \& Administration*;

Libraries, Medical/Organization \& Administration*; Library Collection Development; Library

Materials/Organization \& Administration*; Organizational Innovation; Program Evaluation;

Regional Medical Programs

\section{BACKGROUND}

Established in 1856, Providence Health \& Services (PH\&S) is a not-for-profit Catholic health care system with locations in Alaska, Washington, Montana, Oregon, and California. Currently, PH\&S is the sixth largest not-for-profit health care system and twelfth largest nongovernmental system overall in the United States [1]. Consisting of 26 large and 9 small acute-care hospitals and hundreds of clinics, PH\&S employs 76,201 people, staffing 8,132 acute-care beds. The physical libraries described in this paper are spread throughout the system with 1 Montana, 3 Washington, 2 Oregon, and 3 California locations.

With the affiliation of Swedish Health Service in 2012, PH\&S faced the challenge of establishing structures to deliver shared services throughout the new enlarged system. The library staff recognized the risks and opportunities of delivering services under a unified umbrella and began the process of creating a shared operations model. Drawing on experience from the Oregon library joint structure established in 2013 [2] laid the groundwork for a wider system model. This case study describes the model used to unify a diverse library system into a common department.

\section{STRATEGIC PLANNING}

In 2013, a formal effort for systemizing library services started. In early planning, library staff identified the barriers to unified service: funding, staffing, management engagement and understanding, and the current resource landscape. With these barriers in mind, the library planning group began formulating a model to deliver unified service.

Many concerns arose from changes in the organization's approach to the libraries over the previous decade. In 2004, our health care system had 16 physical libraries and 25 full-time staff members. Ten years later, the number of physical libraries had been reduced by $19 \%$ and the library staff had been 
reduced by $40 \%$. Of the positions requiring a master's degree, $66 \%$ had been eliminated. During this same time period, subscription spending had migrated out of the library budgets, with only $20 \%$ of the total subscriptions budgeted inside a library department, which matched trends noted in the literature [3].

We then developed four strategic goals:

- To create a model for unified library operations

- To create a more professional internal staffing model

- To define a sustainable plan for the libraries' physical spaces

- To reevaluate the collection and services held internally

\section{JOINT SERVICE FORMATION}

\section{Selection of the operating model: the holding company}

PH\&S operates over a thousand separate business entities, each with their own subdepartments. These combined entities spend more than $\$ 13$ billion annually. This scale makes accounting tasks like identifying library departments or quantifying subscription spending very difficult. In the early days of planning, it became clear, from an accounting perspective, that the system could not support a goal of unifying all library assets. Instead, we needed an operating model that would let us grow over time. We looked for a model that fit our strategic goals and allowed each library to provide unique services. The holding company, a model drawn from business, provided the basis for our new structure.

A public holding company holds businesses and assets primarily to grow stock value [4]. Its growth is dictated by the merits of a given investment and the partnerships that can be forged. Using this business model as a template, we selected a library holding group as our model of operations to support our goals, allowing us to target resources outside of the original library budget to expand services. In addition, the model allowed us to exclude resources that did not fit the needs for current library services. The notion of moving internal assets to create a unified service was appealing. Our simplified goal became "to hold information assets to grow evidence-based practice" in our facilities.

\section{Resources}

To form the library holding group, we had to identify potential resources and ask for them. We identified 436 nonlibrary departments that had at least 6,100 subscriptions. To date, 256 nonlibrary departments have transferred 2,138 subscriptions and resources into the library holding group, which is a $59 \%$ success rate by department or a 35\% success rate by subscription. This calculation excludes personal subscriptions, journals and newspapers used in lobbies, patient-focused materials, and resources that are not tracked in our accounting systems.

The new department holds hundreds of thousands more dollars in subscriptions than would have occurred simply by combining the library departments. The library holding group now holds approximately $35 \%$ of organizational subscriptions by number or $26 \%$ by dollar. In addition, 11 of the 14 library departments have joined the group. The formation of this holding group occurred over 2 years, 2014 and 2015 (Figure 1).

\section{Staffing}

Once we selected a model, we reviewed the full-time employees (FTEs) and treated them as assets to be potentially acquired. A good employee, after all, can be the reason to acquire a company in the corporate world. A good librarian would have similar value to us [5].

We found 14 positions to potentially include in the holding group. Positions excluded from consideration had greater than $50 \%$ of their work duties devoted to nonlibrary activities, such as continuing medical education. The idea of a central library department was a major selling point to potential library staff members, because, for many, it represented their first opportunity to work with other library professionals.

Of the 14 FTE potential positions, 14 were ultimately included in the holding group. The change to the holding group prompted 2 retirements and 1 voluntary exit from the company. Turnover consisted of 2 part-time ( 0.6 FTE and 0.12 FTE) and 1 full-time (0.8 FTE) employees. Overall turnover equaled 1.52 FTEs or $11 \%$ of the staff, which was well below the company average for annual turnover $(15 \%+)$. In total, the department hired 5 FTEs $(2$ FTEs were internal library hires into new roles) and rewrote 7 position descriptions to create the new 


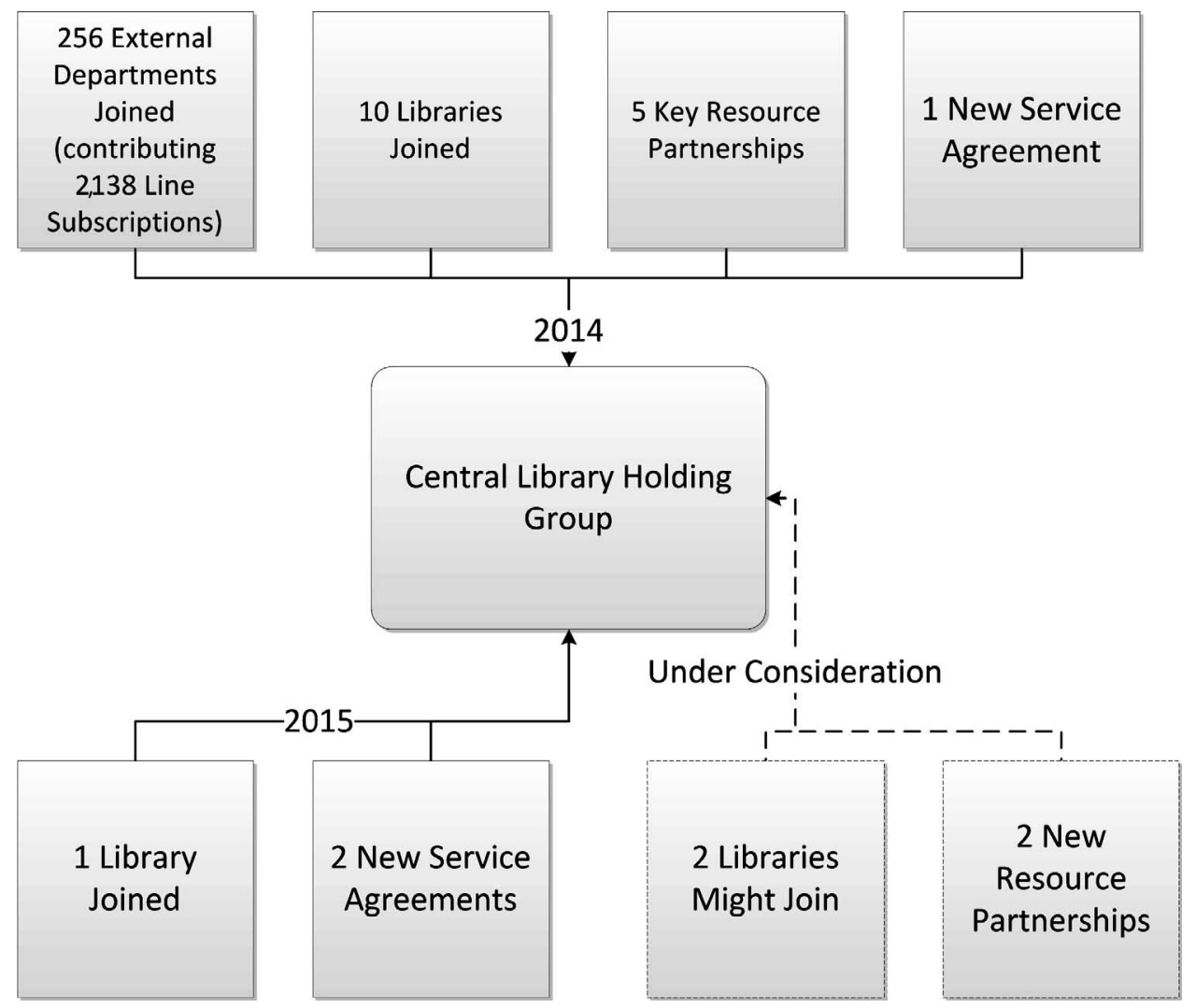

Figure 1

How the library group is formed

shared system structure. The system netted 1.48 more working employees by filling long-vacant positions.

\section{Library space}

The physical libraries in the system ranged from well-maintained, public sites to cramped, isolated spaces. Some libraries had many linear feet of storage, while others had minimal collection space. Fourteen system libraries were considered as holding group candidates. Two sites were excluded because their staffing consisted of medical educators, and one site was excluded because of the parent organization's newly acquired status. After reviewing the sites, the library holding group created space-planning documents that called for reducing physical storage space in favor of more public, collaboration-focused learning spaces that would accommodate two library staff members. This practice is consistent with the current direction in use of space $[6,7]$.

Of the 14 potential library spaces, 11 joined the library holding group. Within a year, the 2 smallest spaces were closed. One location was already slated for closure, and 1 was closed because it lacked equipment, collection, and staffing. Holdings, equipment, and staff (0.12 FTE) were absorbed into primary sites. One additional site was remodeled, reducing the amount of physical space but enhancing learning and collaboration space. These site closures and remodeling reduced the square footage that the libraries occupied by $17 \%$. As our collection moves to electronic platforms, our spaces need to adapt to current space trends [7-9].

\section{Collection and service}

Philosophies around collection development were the most variable piece of library operations. Some sites collected $100 \%$ print, while others collected $98 \%$ digital. This difference in collection philosophies was identified as the largest challenge in working toward a joint structure. Although a holding group can accommodate different operational parameters at 
different sites, a joint collection was identified as a key opportunity in a shared structure. Our review of the current library collection philosophy supported moving toward an e-collection [10-12].

Between a primarily print and primarily digital collection strategy, we opted for a strategy that was $99.95 \%$ digital and $0.05 \%$ print (by dollars). To date, the library has received a single formal complaint about the shift in collection strategies. The holding group did not have baseline circulation figures.

The libraries in the holding group still operate with a fair amount of autonomy. However, the use of a common set of resources has led to a common service catalog consisting of literature searches, current awareness searches, document delivery and interlibrary loan, table of contents service, specialized research, and training. The addition of current awareness searches and table of contents searches is aimed at pushing content to providers. With the combined resources and staff, the library is also taking a wider role in clinical education and training.

\section{RESULTS}

The creation of a library holding group has resulted in growth in services, staff, and access. The subscriptions managed by the library have increased by $26 \%$. Staff changes have increased the impact of the library services. We hired 2 new employees with master's degrees in library science, and the department increased by 1.48 FTEs overall. The service also expanded its patron base to cover $34 \%$ more of the total system. At least 26,018 more employees gained access to resources. Three new service offerings also became part of our service catalog.

There have been tradeoffs in the process. Because space is at a premium at some sites, the library holding group opted to give up $17 \%$ of its square footage as we shifted to a primarily digital collection. The newly remodeled space, while smaller, is more usable. We had to let go of some of the ambiance of hospital libraries lined with shelves of medical journals. However, our digital titles are currently getting 503\% more use than their print counterparts. We facilitated 1,515,112 digital searches, resulting in 368,161 digital article downloads.

One of the biggest advantages of this model is the increase in efficiency. The cancellation of duplicate subscriptions and the consolidated contracting has saved the organization $\$ 321,000$, averaging just over $\$ 9,700$ per site. Although the savings have varied from site to site, there is a correlation between the number of subscriptions transferred and the dollars saved.

\section{DISCUSSION}

The holding group provides a good model for growing library services. In developing this business model for use in our health care system, we learned several lessons. The primary challenges of this model included negative external image impressions, disruption of familiar library staff duties and roles, and difficulty providing services to some patrons. In addition to the cost savings, we believe the primary benefits of this model include better management of subscription services, a reporting structure that makes sense to library employees, greater collegiality among library staff, a centralized space plan, and combined efforts in collection and service delivery. Although challenges remain, the library holding group's success points to a viable model of unified operations for specialty libraries, especially for those in a large corporate entity.

\section{REFERENCES}

1. Marshall E. 10 largest nonprofit hospital systems | 2015. Becker's Hosp Rev [Internet]. 2015 [cited Feb 25 2016].

$<$ http://www.beckershospitalreview.com/lists/10-largestnonprofit-hospital-systems-2015.html $>$.

2. Martin HJ, Delawska-Elliott B. Combining resources, combining forces: regionalizing hospital library services in a large statewide health system. J Med Libr Assoc. 2015 Jan;103(1):44-8. DOI: http://dx.doi.org/10.3163/1536-5050. 103.1.009. PubMed PMID: 103873098.

3. Thibodeau PL, Funk CJ. Trends in hospital

librarianship and hospital library services: 1989 to 2006. J Med Libr Assoc. 2009 Oct;97(4):273-9. DOI: http://dx.doi. org/10.3163/1536-5050.97.4.011. PubMed PMID: 45060978.

4. Bobo J. Mutual holding companies-essential for a competitive marketplace. National Underwriter/ LifeHealth Financial Serv. 1998;102(30):19.

5. McCloskey DJ. Providing remarkable customer service and resources across a health care system. J Hosp Libr. 2012;12(1):86-90. DOI: http://dx.doi.org/10.1080/ 15323269.2012.638259. PubMed PMID: 104484487. 6. Allee NJ, Blumenthal J, Jordan K, Lalla N, Lauseng D, Rana G, Saylor K, Song J. One institution's experience in transforming the health sciences library of the future. Med Ref Serv Q. 2014;33(1):1-16. DOI: http://dx.doi.org/ 
10.1080/02763869.2014.866444. PubMed PMID:

104030059.

7. Persily GL, Butter KA. Reinvisioning and redesigning

"a library for the fifteenth through twenty-first centuries": a case study on loss of space from the Library and Center for Knowledge Management, University of California, San Francisco. J Med Libr Assoc. 2010 Jan;98(1):44-8. Epub 2010/01/26. DOI: http://dx.doi.org/10.3163/15365050.98.1.015. PubMed PMID: 20098654; PubMed Central PMCID: PMCPMC2801976.

8. Shipman JP, Stoddart JM, Peay WJ. Building projects: redefining hospital libraries. J Med Libr Assoc. 2012 Jul; 100(3):166-70. DOI: http://dx.doi.org/10.3163/1536-5050. 100.3.005. PubMed PMID: 108140888.

9. Tooey MJ. Renovated, repurposed, and still "one sweet library": a case study on loss of space from the Health Sciences and Human Services Library, University of Maryland, Baltimore. J Med Libr Assoc. 2010 Jan;98(1): 40-3. DOI: http://dx.doi.org/10.3163/1536-5050.98.1.014. 10. Beck JB, Tieder JS. Electronic resources preferred by pediatric hospitalists for clinical care. J Med Libr Assoc. 2015 Oct;103(4):177-83. DOI: http://dx.doi.org/10.3163/ 1536-5050.103.4.003. PubMed PMID: 110663370.

11. Shearer BS, Klatt C, Nagy SP. Development of a new academic digital library: a study of usage data of a core medical electronic journal collection. J Med Libr Assoc. 2009 Apr;97(2):93-101. DOI: http://dx.doi.org/10.3163/ 1536-5050.97.2.005. PubMed PMID: 40097801.
12. Ritchie A, Skoglund H. Ebooks at Barwon Health Library: a case study. Australian Libr J. 2015;64(3):180-93. DOI: http://dx.doi.org/10.1080/00049670.2015.1048042.

PubMed PMID: 108394501.

\section{AUTHORS' AFFILIATIONS}

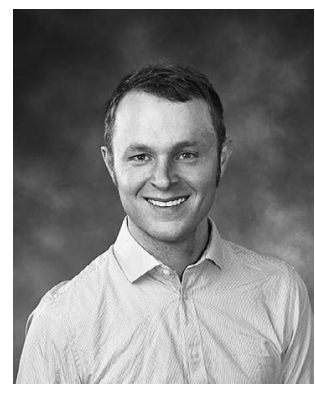

Isaac R. Huffman, MSLS, AHIP, isaac.huffman@ providence.org, Director of System Library Services, Providence Health \& Services, Washington, Corporate Office, 1801 Lind Avenue Southwest, Renton, WA 98057; Heather J. Martin, MISt, AHIP, heather.martin@ providence.org, Director of Regional Library Services for Alaska California and Oregon, Providence Health \& Services, Oregon, Providence Portland Medical Center, 4805 Northeast Glisan Street, Portland, OR 97213; Basia Delawska-Elliott, MLIS, barbara.delawska-elliott@providence.org, Medical Librarian, Providence Health \& Services, Oregon, Providence St. Vincent Medical Center, 9205 Southwest Barnes Road, Portland, OR 97225

Received March 2016; accepted May 2016 